\section{Zahlen des Monats}

\section{Flüssiger}

Bundesgesundheitsminister Hermann Gröhe hat es gut. Im nächsten Jahr darf er mehr Geld ausgeben als bisher. Wie aus dem Entwurf des Bundeshaushaltes für 2016 hervorgeht, steigt der Etat für Gröhes Ministerium um 2,5 Milliarden Euro auf 14,6 Milliarden Euro. Und mit dem Ausgabenanstieg von 20 Prozent liegt das BMG an der Spitze aller Ministerien. Wobei das BMG mit seinen Ausgaben selbst im Mittelfeld der Ministerien liegt. Der satte Etat-Anstieg geht auf die Erhöhung des Steuerzuschusses für den Gesundheitsfonds zurück.

\section{Älter}

Der Altersdurchschnitt in deutschen Arzt- und Zahnarztpraxen lässt aufhorchen. Wie das Statistische Bundesamt mitteilt, waren Ende 2013 insgesamt 65 Prozent der in Praxen tätigen Ärzte und Zahnärzte mindestens 50 Jahre alt. Jeder vierte hatte sogar das sechzigste Lebensjahr überschritten. In den Altersgruppen der mindestens 50-Jährigen sind laut Statistik Psychotherapeuten mit 69 Prozent und Zahnärzte einschließlich Kieferorthopäden mit 50 Prozent überdurchschnittlich vertreten. Im Vergleich dazu waren von den insgesamt 5,1 Millionen Beschäftigten im Gesundheitswesen 36 Prozent 50 Jahre und älter.

\section{Zurückhaltender}

Fast jede zweite Zahnarztpraxis wird von einer Frau gegründet. Dennoch entscheiden sich Zahnärztinnen öfter für eine Anstellung als ihre männlichen Kollegen. Das geht aus der Existenzgründungsanalyse Zahnärzte 2014 hervor, die von der Deutschen Apotheker- und Ärztebank und dem Institut der Deutschen Zahnärzte durchgeführt wurde. Danach lag der Anteil der weiblichen Existenzgründer 2014 bei 48 Prozent. Demgegenüber stehen 64 Prozent Zahnmedizinstudentinnen. Das weist laut apoBank daraufhin, dass sich Frauen immer noch eher für die Anstellung entscheiden als für die Selbstständigkeit. Die Analyse zeigt auch, dass Zahnärztinnen mit durchschnittlich 231.000 Euro bei einer Praxisübernahme weniger in die Existenzgründung investieren als die männlichen Kollegen.

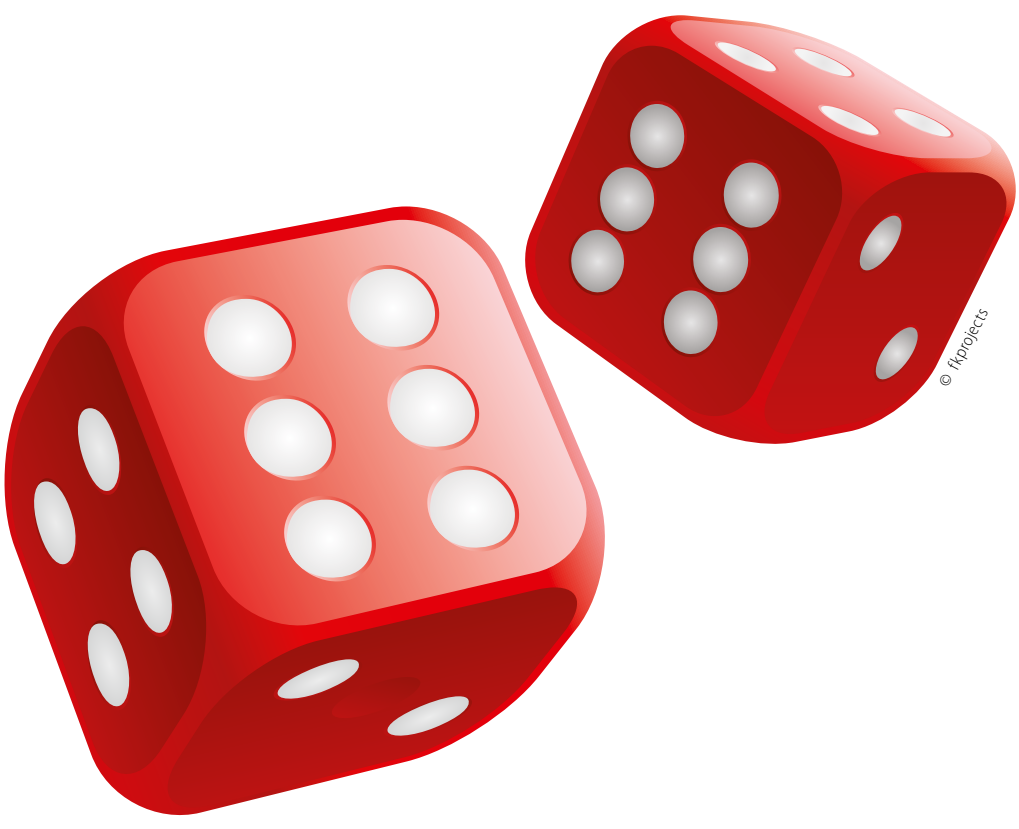

Unabhängige Patientenberatung

\title{
Zuschlag geht an Sanvartis
}

Die Würfel sind gefallen: Das CallcenterUnternehmen Sanvartis wird ab 2016 die Unabhängige Patientenberatung (UPD) übernehmen. Wie das Bundesgesundheitsministerium (BMG) Mitte September bekanntgab, einigten sich der Spitzenverband der Gesetzlichen Krankenkassen und der Patientenbeauftragte der Bundesregierung, Karl-Josef Laumann (CDU), auf das Duisburger Unterneh- men. Zuvor hatten Ärzte- und Zahnärzte die voraussichtliche Vergabe der Patientenberatung an Sanvartis scharf kritisiert. Hintergrund: Sanvartis ist bereits Dienstleister für Krankenkassen und Pharmaindustrie. Die Vergabekammer des Bundes bescheinigt dem Duisburger Unternehmen jedoch die „vorgeschriebene Neutralität und Unabhängigkeit“.

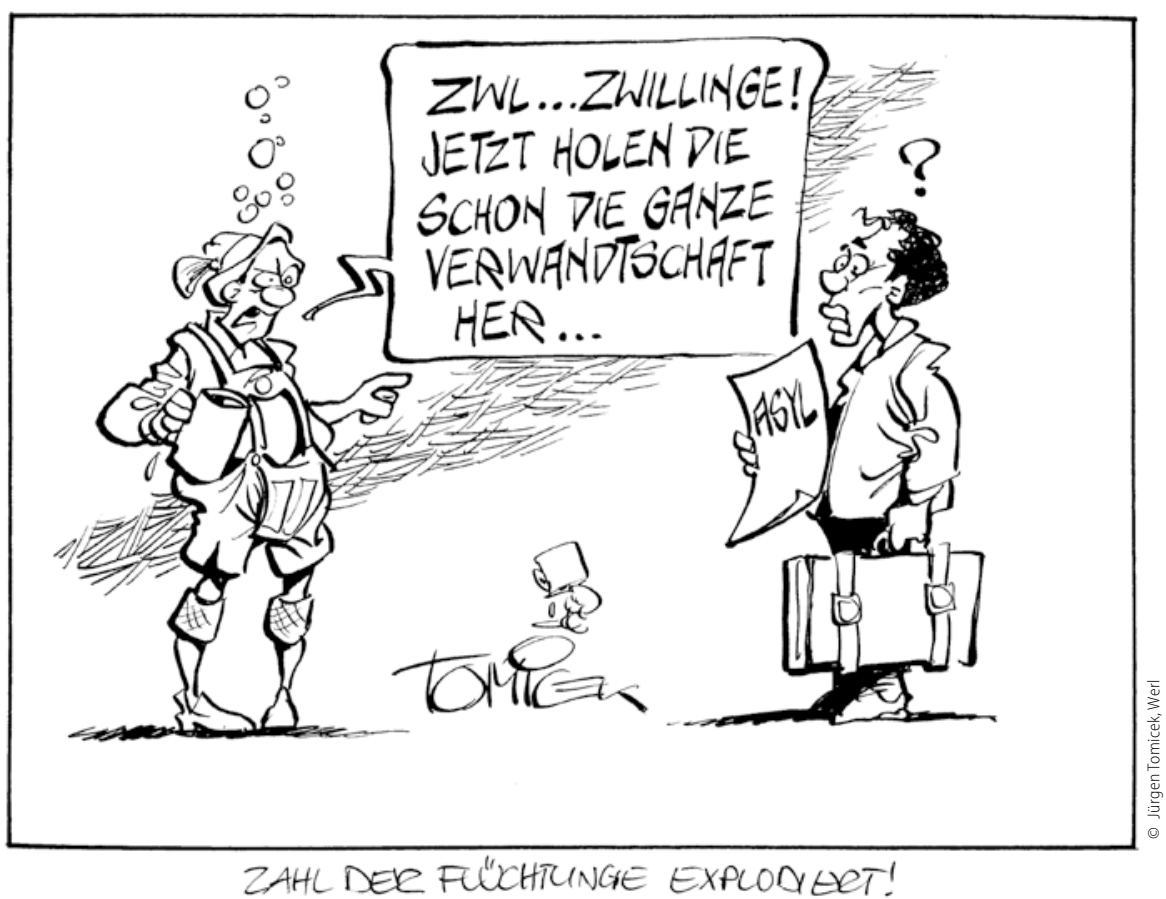

